\title{
A ALEGORIA TROPICALISTA NA AVENIDA VAZIA DO HISTORICISMO: O TROPICALISMO E O ROCK NO BRASIL
}

\author{
Tiago Hermano Breunig ${ }^{1}$ \\ Jair Tadeu da Fonseca ${ }^{2}$
}

\begin{abstract}
Resumo: A compreensão do Tropicalismo pelos intelectuais no Brasil o remete, desde a sua consolidação na cultura brasileira, a uma forma de representação associada com a alegoria, constitutiva do moderno e do nacional, que se relaciona, no entanto, ao tempo do evolucionismo vazio, do progresso linear da historiografia historicista. Assim, a alegoria se aproxima de uma atualização das representações do Brasil. Para tanto, como observa Carlos Basualdo, o rock se configura como um meio de atualizar a produção musical no Brasil pela incorporação de seus elementos. Mas se o Tropicalismo, conforme a natureza da alegoria, sintetiza dialeticamente as polaridades representadas, por um lado, pela MPB e, por outro, pelo rock, interessa como o rock, por sua vez, produz um contradiscurso da identidade nacional por meio de um procedimento que se nega a operar logicamente ou dialeticamente, o que constitui o objeto do presente artigo.
\end{abstract}

Palavras-chave: Rock. Tropicalismo. Nacionalismo.

A compreensão do Tropicalismo pelos intelectuais no Brasil o remete, desde a sua consolidação na cultura brasileira, a uma forma de representação associada com a alegoria. Segundo Christopher Dunn (2007, p. 66), "Roberto Schwarz foi o primeiro a comentar como a alegoria moderna", tal como conceitualizada por Walter Benjamin, ou seja, como "um modo de representação" que "resiste a categorias totalizadoras transcendentes", era desenvolvida no Tropicalismo.

Com efeito, a partir da concepção benjaminiana de alegoria, Schwarz (1978, p. 74) compreende o Tropicalismo como uma "submissão de anacronismos" ao moderno, cujo resultado consiste em uma "alegoria do Brasil". Com a "alegoria tropicalista", em que se combinam indistintamente o passado e o presente, o arcaico e o moderno, os tropicalistas, segundo Schwarz (1978, p. 78), “alegorizam a 'ideia' intemporal de Brasil”. Dunn (2007, p. 66-69) conclui que o Tropicalismo, conforme o concebe Schwarz, "representava o Brasil como um absurdo", ao apresentar as suas contradições "como emblemas de identidade nacional".

O que se pode imediatamente reter da concepção da alegoria tropicalista condiz com o fato de constituir uma representação moderna, por um lado, e nacional, por outro. Assim, a alegoria tropicalista representa algo como uma atualização das representações do Brasil. Tanto que Carlos Basualdo (2007, p. 13-15) afirma que o Tropicalismo

\footnotetext{
${ }^{1}$ Doutorando em Literatura - UFSC. Bolsista do CNPq.

Lattes: http://buscatextual.cnpq.br/buscatextual/visualizacv.do?id=K4744709D6

${ }^{2}$ Doutor em Estudos Literários - UFMG. Professor Adjunto - UFSC.

Lattes: http://buscatextual.cnpq.br/buscatextual/visualizacv.do?id=K4790533Y9
} 
pretende "pensar a identidade nacional brasileira como um processo aberto, em desenvolvimento permanente" e, para tanto, o rock se configura estrategicamente "como meio de atualizar e potencializar a produção musical no Brasil” pela incorporação de seus elementos no contexto da tradição musical brasileira.

Embora a incorporação de elementos do rock deva ser compreendida como o processo mesmo, em detrimento do seu resultado, como observa Carlos Basualdo (2007, p. 15), o Tropicalismo contraditoriamente preserva algo das noções de forma e de formação, com suas normas e valores comuns, na medida em que pretende "fundar", ao seu modo, "a identidade nacional". A "retomada da "linha evolutiva", proposta por Caetano Veloso e desenvolvida criticamente por Augusto de Campos, no processo de institucionalização da MPB o comprova definitivamente.

Acontece que, paradoxalmente, a alegoria tropicalista se associa, assim, ao tempo iluminista do progresso linear, o tempo do evolucionismo vazio. Benjamin (1994, p. 229) compreende o progresso, como o concebe a historiografia historicista, como uma "marcha no interior de um tempo vazio". Ao acompanhar a referida marcha, o Tropicalismo se reduz a uma alegoria... de carnaval, de modo que, na marcha pelas avenidas do Brasil, o bloco tropicalista da historiografia historicista se confunde com o cortejo triunfal, cujos despojos constituem "o que chamamos bens culturais". (BENJAMIN, 1994, p. 225) Afinal, "não existem”, como questiona Benjamin (1994, p. 223), "nas vozes que escutamos, ecos de vozes que emudeceram?"

\section{O TROPICALISMO E A INSTITUCIONALIZAÇÃO DA MPB}

As propostas musicais marioandradinas visavam, desde fins dos anos 1920, a uma "continuidade nacional", no interior da qual as manifestações musicais populares exerceriam "uma função verdadeiramente nacional e social" (COLI, 1998, p. 24), conforme estabelece sua proposta de nacionalização musical, que adquire um contorno partircular a partir dos tempos ditatoriais do Estado Novo. Apesar de se direcionar ao campo musical erudito, a proposta marioandradina parece germinar no campo musical popular e reflorescer nos anos 1960 e 1970, sobretudo depois dos acontecimentos de 1964 e 1968.

Ao propugnar a concepção de "normas caracteristicamente brasileiras" (ANDRADE, 1976, p. 80), que confeririam a "entidade" manifesta pela incorporação de caracteres musicais convencionalmente nacionais, a tradição que se estabelece a partir do pensamento musical marioandradino fundamenta os paradigmas por meio dos quais se pode reconhecer uma "“especificidade musical' brasileira" (SANDRONI, 2001, p. 20 ), traduzida por determinadas figuras que conteriam um significado nacional, como a sincopação considerada caracteristicamente ou legitimamente nacional:

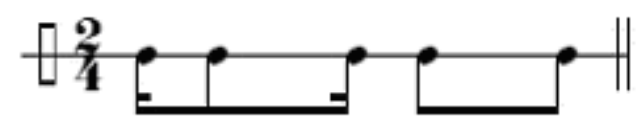


Se as noções de forma e, sobretudo, de formação previstas pela proposta de nacionalização musical implicam a formação e a fixação dos caracteres musicais constitutivos da "entidade" musical brasileira que informariam a MPB, por conseguinte, implicam o conceito marioandradino de "deformação". Os processos de "deformação" pelos quais elementos musicais estrangeiros passam no Brasil consistem em uma "deformação que transforma fontes exclusivamente estrangeiras numa organização que sem ser propriamente original" se torna, segundo Andrade (1976, p. 93), "caracteristicamente nacional".

Em detrimento da forma e da formação previstas e precedidas pelo processo de deformação a partir da formação e da fixação dos caracteres musicais constitutivos de uma musicalidade brasileira elaborada discursivamente a partir do pensamento marioandradino, o rock no Brasil dos anos 1970 recorre, ironicamente, a processos de deformação. A deformação dos paradigmas que informam a MPB pelo rock no Brasil funda um discurso que problematiza a naturalidade dos ritmos brasileiros por meio de uma contradição que desnaturaliza conceitos de valor evidentes.

Como modelo de um procedimento que opera sobre os elementos musicais e textuais das canções, a apropriação pelo rock brasileiro de versos de "Aquarela do Brasil" sob uma nova melodia e harmonia exemplifica o processo de deformação, previsto nas pesquisas marioandradinas, como emprego de textos tradicionais subordinados a melodias novas:
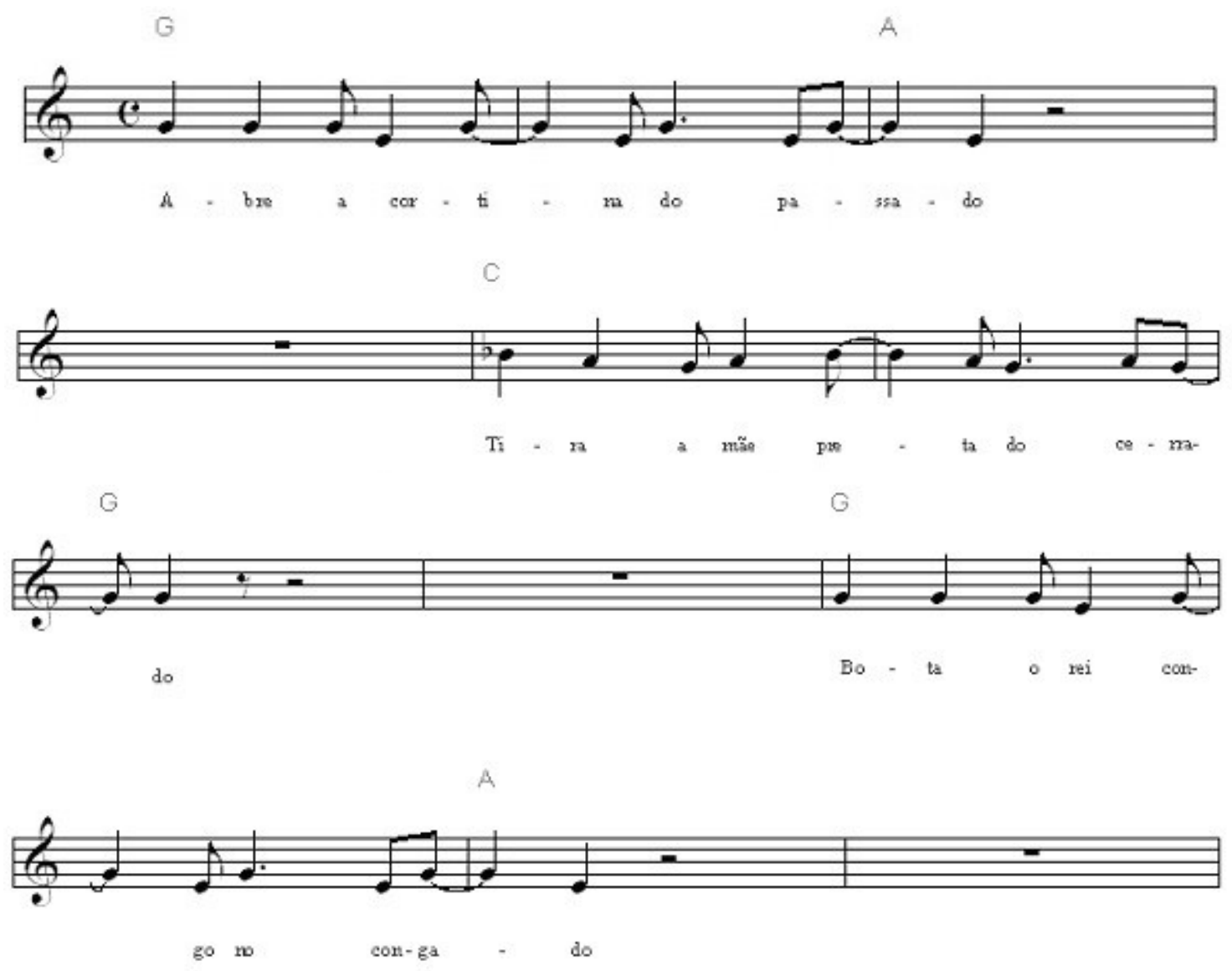


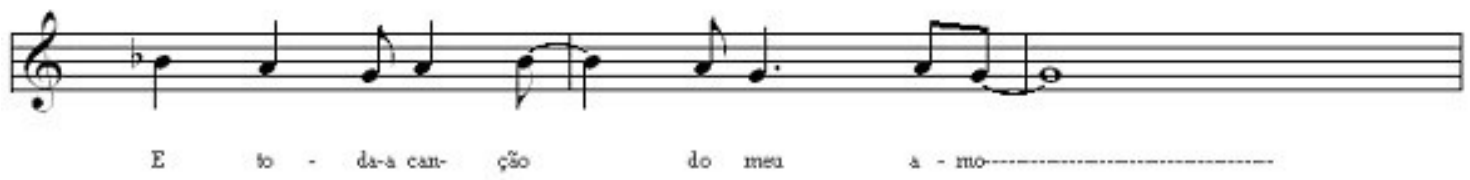

G

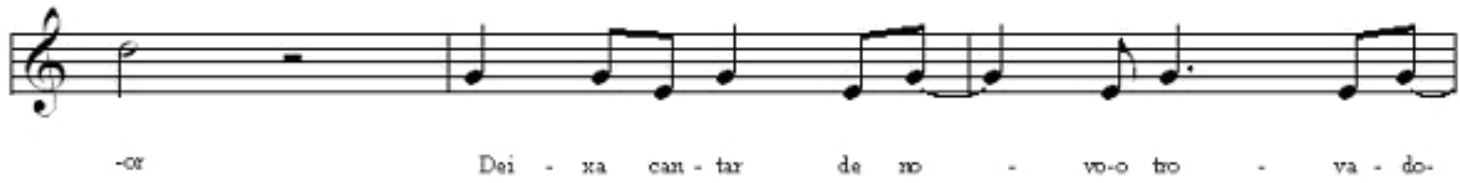

A
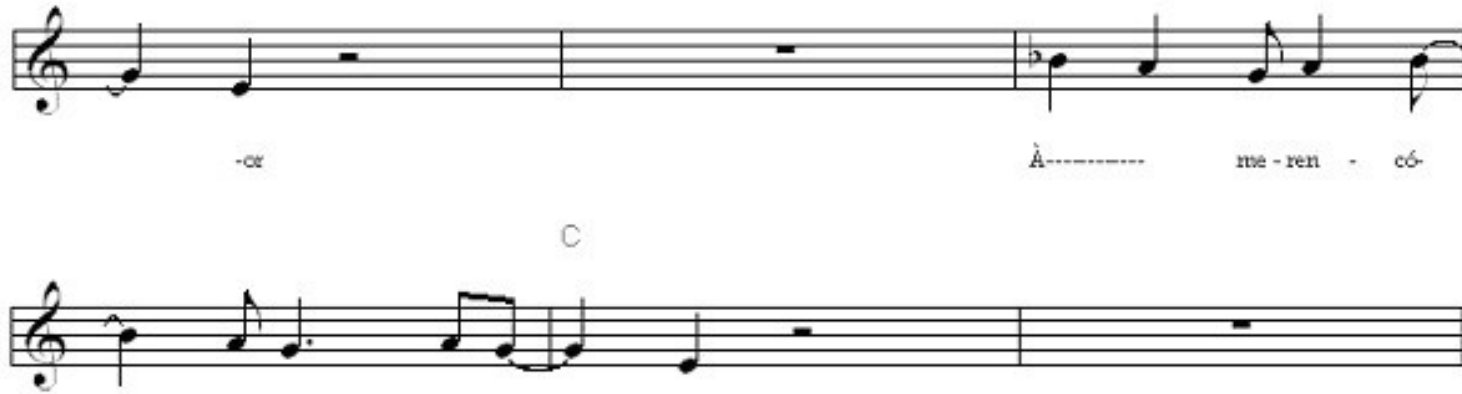

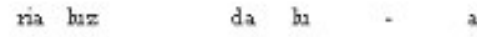
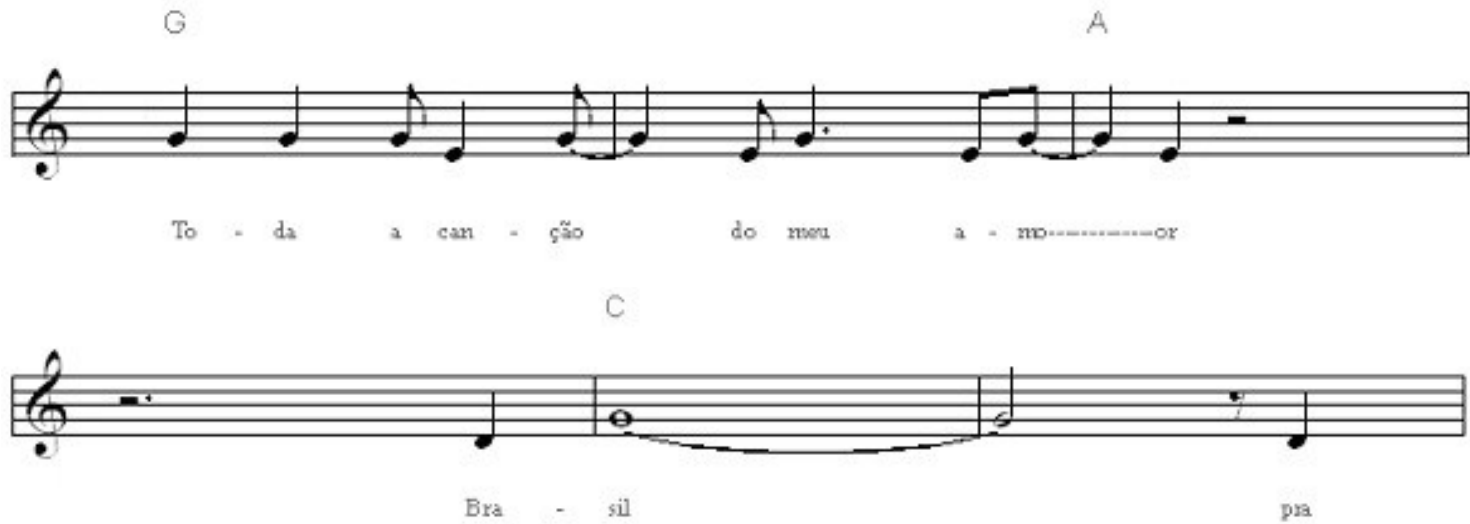

G

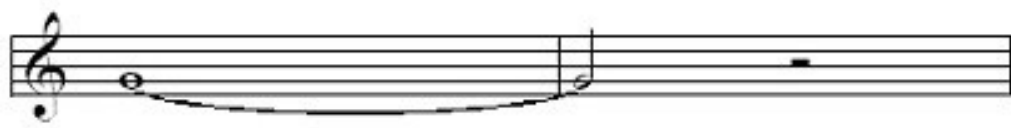

mim

Abre a cortina do passado

Tira a mãe preta do cerrado

Bota o rei congo no congado

E toda a canção do meu amor

Deixa cantar de novo o trovador

À merencória luz da lua

Toda a canção do meu amor

Brasil! Pra mim... 
A apropriação de versos de Aquarela do Brasil interessa na medida em que a canção, considerada a origem do samba exaltação, caracterizado pelo ufanismo do Estado Novo, representa o paradigma do segmento nacionalista que culmina com a "consolidação do samba como padrão de música brasileira" (NAPOLITANO; WASSERMAN, 2000, p. 172), na contramão da proposta de nacionalização musical marioandradina.

Ao processo de apropriação dos versos tradicionais sob uma nova melodia descrito acima antecede imediatamente uma progressão equivalente ao acompanhamento dos versos apropriados da canção original, de modo que o compasso dois por quatro $-\underset{\mathbf{4}}{\mathbf{2}}$ - do samba, reproduzido a partir da canção tradicional, cede ao compasso quatro por quatro $-\frac{\mathbf{4}}{\mathbf{4}}$ ou $\mathbf{C}$ - do rock:

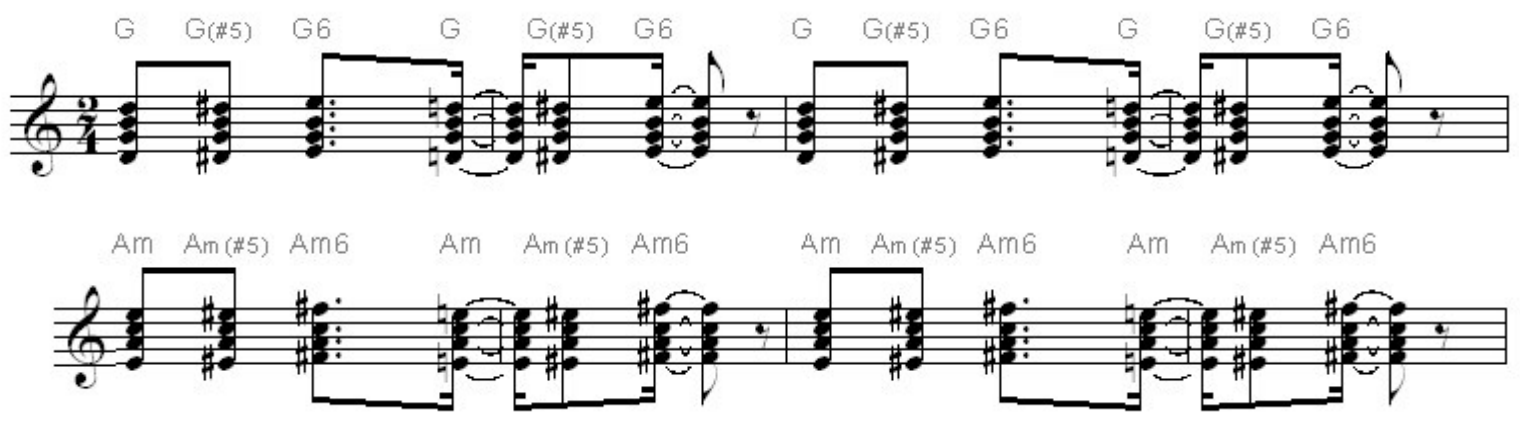

Os versos propostos a cantar o Brasil brasileiro do samba que circulou sob estilo definido como "cena brasileira" nos anos do Estado Novo se ressignificam na medida em que se recortam e se deslocam no respectivo processo. O referido rock brasileiro assume a tarefa a que se atribui o sujeito da canção de cantar o Brasil nos seus versos, de modo que interessam os sentidos produzidos pelos versos deslocados para o contexto em que emerge um outro sentido para o verso "Brasil! Pra mim...", tanto quanto os sentidos produzidos pelos versos emudecidos:

\footnotetext{
É o Brasil brasileiro

Terra de samba e pandeiro

Brasil! Brasil!

Pra mim... Pra mim...
}

Posteriormente, a mesma banda que se apropria dos versos de "Aquarela do Brasil", subvertendo os sentidos do samba de Ary Barroso, cantaria em "Uma banda made in Brazil": 
Quem não me entende

Diz que a terra é do samba

E aqui não tem lugar para a gente... ${ }^{3}$

Assim, se no Brasil se forma um sistema cultural diferenciado para o sistema musical em torno da MPB e se, como afirma Marcos Napolitano (2001), a configuração do conceito de MPB ocorre a partir do Golpe de 1964 e se consolida em 1968, depois do Tropicalismo, o conceito se estabelece como uma instituição cultural capaz de atribuir uma identidade nacional e popular, bem como legitimar a hierarquia cultural. $\mathrm{O}$ processo instituinte ocorre concomitantemente ao debate em torno do engajamento musical como redimensionamento com a tradição com fins de popularização e afirmação nacional em contraposição ao rock, compreendido como o outro contra o qual se afirma a identidade nacional e como a contraface do golpe de 64 , ao passo que a MPB permaneceria associada aos discursos de autenticidade, origem, etc.

Em outras palavras, enquanto o duvidoso conceito de MPB mantinha uma "certa função de 'defesa-nacional"' (SANDRONI, 2004, p. 29), ironicamente consoante ao projeto cultural do Estado, o rock no Brasil dos anos 1970 produz sentidos a partir da incorporação de caracteres preestabelecidos nos discursos acerca do que se compreende como nacional. Nesse sentido, ao confrontar os aspectos constitutivos da cultura brasileira e da identidade nacional presentificados na MPB, o rock, no Brasil, suspende a dicotomia entre o nacional e o estrangeiro ou a MPB e o rock, conservando, no entanto, os opostos da polaridade que sustenta o discurso musical nacionalista.

\section{O PROCEDIMENTO DO ROCK NO BRASIL}

Antes de o Tropicalismo promover o "deslocamento dos instrumentos" da Jovem Guarda para a MPB, como constata Augusto de Campos (2008, p. 154), o rock desloca instrumentos e sonoridades de manifestações musicais regionais e populares do Brasil. Afinal, o advento do rock and roll remonta a meados dos anos 1950, com as interpretações e traduções brasileiras dos originais provenientes dos Estados Unidos, eventualmente adaptadas com instrumentos populares ou regionais, como o acordeom, a exemplo da versão instrumental de "Rock around the clock", de Bill Haley and his Comets, composta pelo acordeonista Frontera em 1955, como que confirmando a contraditoriedade interna que, conforme Richard Middleton (1990, p. 18), caracteriza o rock. Se o deslocamento constatado por Augusto de Campos "tem, em si mesmo, um significado", certamente o tem os deslocamentos propostos pelo rock no Brasil. Apenas

\footnotetext{
3 A contracapa do disco, que empresta o nome de uma obra fundamental do modernismo brasileiro publicada no mesmo ano da Semana de Arte Moderna, qual seja, "Paulicéia desvairada", referencia a pluritonalidade da obra marioandradiana em detrimento do passadismo nacionalista, ao citar os versos de um poema de "Losango Caqui", de 1924: “O passadista se enganou. Não era desafinação, era pluritonalidade moderníssima." Na mesma contracapa, a banda, ao dedicar o disco a Elvis Presley e a Erasmo Carlos, estabelece uma ponte entre o rock and roll, a jovem guarda e o rock produzido no Brasil dos anos 1970: "O Made dedica Paulicéia desvairada a Erasmo Carlos e a Elvis Presley”.
} 
em 1957, ano de que datam as primeiras composições brasileiras em ritmo de rock, a guitarra seria utilizada em um rock composto por Betinho e seu Conjunto.

A consolidação do rock and roll no mercado musical brasileiro provoca o aparecimento de compositores e versionistas de sucessos do ritmo para a interpretação de cantores brasileiros, bem como de bandas instrumentais influenciadas pelos ritmos da surf music, do twist e do hully-gully. O oposicionismo moral e politicamente orientado que o rock confronta desde o seu advento no Brasil se potencializa com o sucesso da Jovem Guarda em um dilema nacionalista compartilhado pela ideologia do Estado e da oposição ao Estado desde o Golpe de 1964, quando se radicaliza a polarização que dividiu a sociedade brasileira, de modo reducionista, entre o "nacionalpopulismo" e o "nacional-desenvolvimentismo", ambos nacionalistas, portanto, confirmando o aspecto invariavelmente nacionalista que caracteriza a cultura no Brasil nos anos 1960. O referido quadro se agrava com o decreto do AI-5 em dezembro de 1968.

$\mathrm{Na}$ medida em que dialoga com os aspectos constitutivos da cultura brasileira e da identidade nacional, presentificados na MPB, por meio da relativização da dicotomia instaurada no discurso nacionalista musical, o rock no Brasil dos anos 1970 permite entrever as suas contradições. Assim, Raul Seixas, por exemplo, suspende a referida dicotomia ao comparar os ritmos do rock and roll e do baião, respectivamente intercalados nas estrofes da canção:
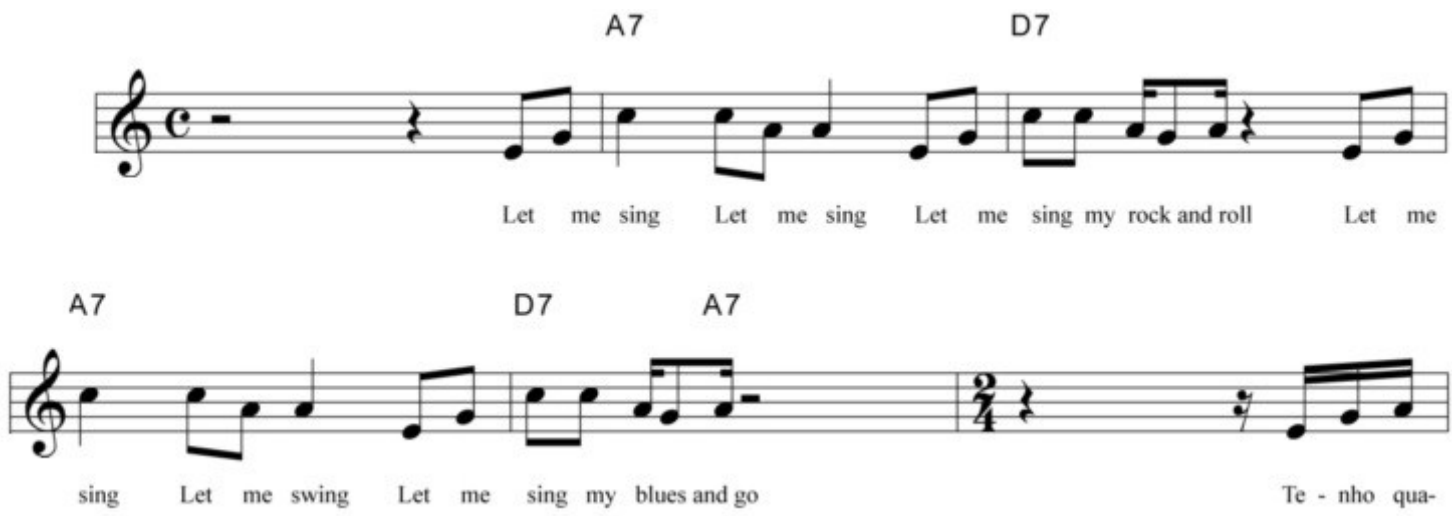

D7

A7

D7

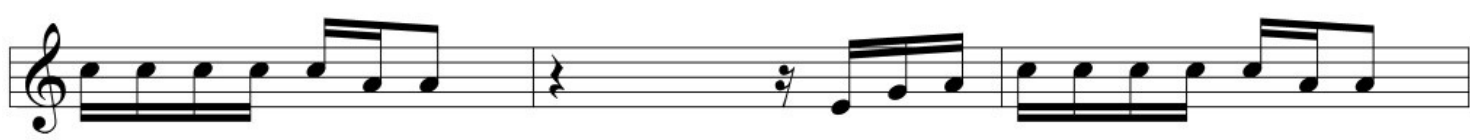

ren - ta e oi - to qui - los certos

Qua - ren - ta e oi - to qui - los de bai - ão

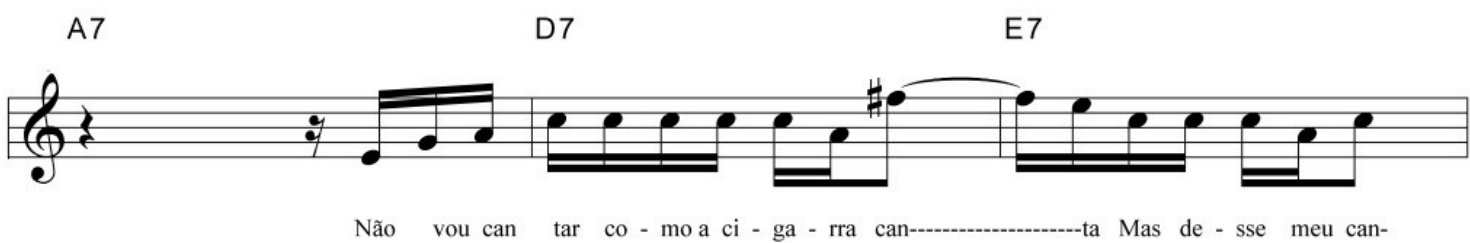




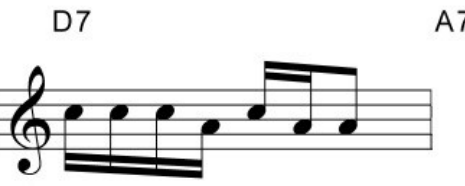

Let me sing, Let me sing

Let me sing my rock and roll

Let me sing, Let me swing

Let me sing my blues and go

Tenho quarenta e oito quilos certos

Quarenta e oito quilos de baião

Não vou cantar como a cigarra canta

Mas desse meu canto eu não abro mão

Ao ceder ao dois por quatro do baião, "Let me sing, let me sing" apresenta um significativo rompimento do compasso quatro por quatro do rock, que subverte o ritmo e produz sentido ao compreender a metade do compasso quatro por quatro no interior de um compasso dois por quatro, como graficamente representado pela partitura:

\section{D7}

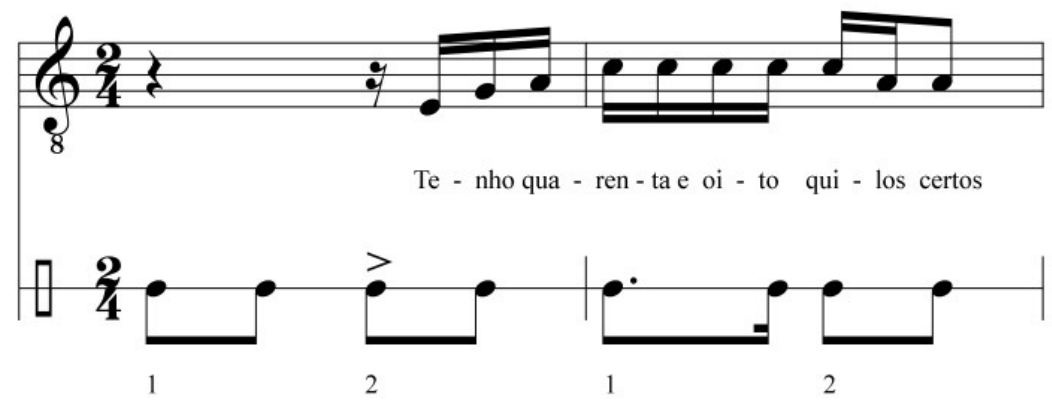

em que se manifesta, portanto, o paradigma que se caracteriza fundamentalmente pela recorrente contrametricidade na quarta semicolcheia do compasso dois por quatro, que antecede e fundamenta a construção dos discursos acerca da musicalidade popular brasileira, sobretudo a partir da autoridade musical marioandradina, que a denomina "síncope legítima" ou "característica" e a julga portadora de uma "especificidade musical" brasileira. Afinal, o referido paradigma estrutura o ritmo do baião:

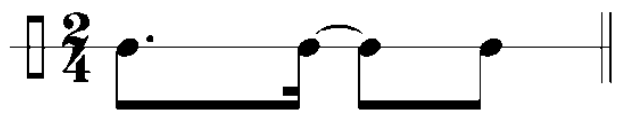


A singularidade de Raul Seixas enquanto representação do rock brasileiro para a historiografia da MPB, no mesmo momento em que o rock emudece diante da demanda por um discurso de identidade nacional, se deve a uma relação com a "musicalidade tradicional da MPB", em cuja historiografia aparece como precursor do "rock brasileiro" (ALBIN, 2003, p. 352), ${ }^{4}$ mesmo a despeito de abdicar da tradição da MPB. Raul Seixas recusa a tradição da MPB e a sua continuidade representada pelo Tropicalismo ao negar a "retomada da 'linha evolutiva",, proposta por Caetano Veloso no debate promovido e publicado pela Revista Civilização Brasileira, cujo objetivo era entender e equacionar os novos desafios compreendidos em termos de engajado ou alienado dispostos com a crise promovida pelo sucesso comercial da Jovem Guarda:

\author{
Acredite que eu não tenho nada a ver \\ Com a linha evolutiva da música popular brasileira \\ A única linha que eu conheço \\ É a linha de empinar uma bandeira
}

O referido debate foi publicado em maio de 1966, mesmo ano, portanto, do disco "Jovem Guarda", da dupla Roberto e Erasmo Carlos. No debate, Caetano Veloso defende a continuidade de uma tradição musical brasileira nos termos de uma "retomada da linha evolutiva" que poderia oferecer "uma organicidade para selecionar e ter um julgamento de criação" (VELOSO apud BARBOSA, 1966, p. 378). A partir das palavras de Caetano Veloso, Augusto de Campos (2008, p. 144) transforma a "linha evolutiva" em palavra de ordem em seus artigos, interpretando a mesma sob o signo da antropofagia de Oswald de Andrade e, musicalmente, como a "abertura experimental em busca de novos sons e novas letras." Ao estabelecer uma ponte discursiva entre a defesa da "linha evolutiva" de Caetano Veloso e o Tropicalismo, Augusto de Campos (2008, p. 145) postula a inutilidade do nacionalismo diante da "intercomunicabilidade universal”, a partir da qual Caetano acabaria “com a 'discriminação' musical entre MPB e jovem guarda."

A necessidade de negar uma continuidade com o Tropicalismo se apresenta como uma necessidade de afirmar o rock como um lugar discursivo e, por conseguinte, social. A negação da tradição da MPB pelo rock no Brasil, contrariamente ao Tropicalismo que, segundo Marcos Napolitano (2001, p. 240), "encerrou uma fase de institucionalização da MPB, através de uma estratégia paradoxal: negando-a (em seu sentido restrito), contribuiu para ampliar e consolidar novo estatuto assumido pela sigla, dentro da hierarquia cultural como um todo", instaura um lugar para o rock que, se se associa a uma narrativa e a uma tradição, condiz com a tradição e a narrativa do rock and roll.

O procedimento que relativiza o rock aos ritmos regionais e populares brasileiros se apresenta como intervenção no debate sobre a MPB, discutido em termos de

\footnotetext{
${ }^{4}$ Com uma preocupação evidentemente historicista, Ricardo Cravo Albin (2003, p. 287) incluiu Raul Seixas em sua historiografia da MPB como o "primeiro artista a misturar sistematicamente o rock com ritmos brasileiros, principalmente o baião".
} 
nacionalidade no quadro da polarização social no limite da politização cultural sofrida na sociedade brasileira. Nesse sentido, o sujeito da canção, ao mesmo tempo em que problematiza a naturalidade dos ritmos brasileiros pela contradição que desnaturaliza conceitos de valor evidentes, contraditoriamente naturaliza a relação do corpo com o ritmo, seja do rock, seja da MPB.

Assim, enquanto o sujeito da canção em Raul Seixas estabelece uma relação do seu corpo com o ritmo do baião, ao equiparar a sua massa corporal, correspondente a exatos quarenta e oito quilos, a uma mesma medida do respectivo ritmo, o sujeito da canção da banda Perfume Azul do Sol associa recorrentemente o mesmo ritmo a um aspecto da fisiologia que se apresenta como fundamental para a manutenção da vida do sujeito. O sentido do verso "o baião é minha respiração" se completa nos versos de outra canção, em que o baião e o forró constituem o sangue do sujeito da canção, cujos versos "carrego triângulo e zabumba e levo no sangue o baião", de "O abraço do baião", se somam aos transcritos abaixo:

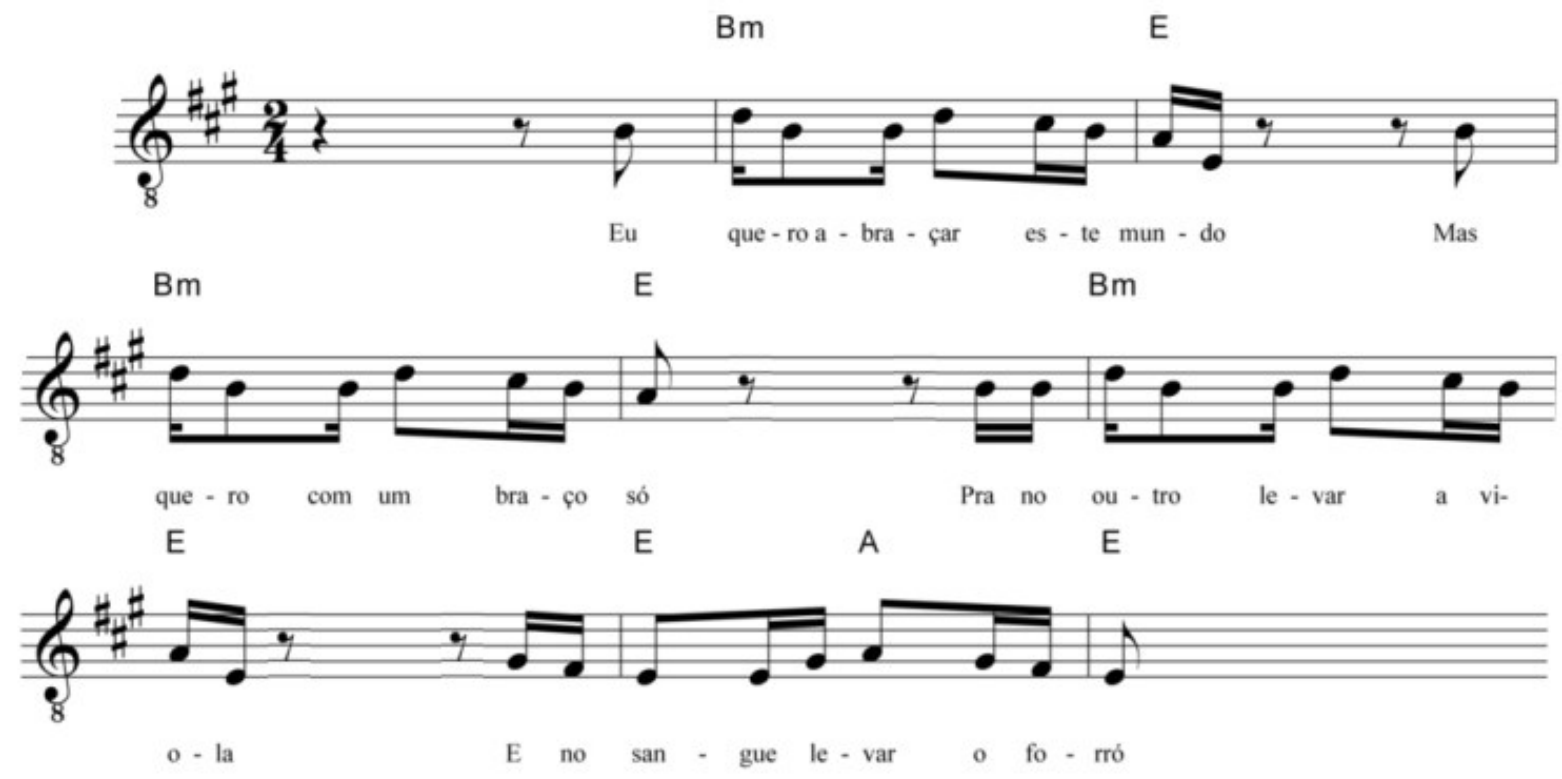

Eu quero abraçar este mundo

Mas quero com um braço só

Pra no outro levar a viola

E no sangue levar o forró

A afirmação em torno dos ritmos constitutivos da MPB, no entanto, contrasta com um fundo falso, qual seja, o rock. Assim, a despeito da forma musical que se depreende da melodia, formada precisamente por uma figura representativa da "entidade" do cancioneiro popular brasileiro expresso por caracteres musicais convencionalmente nacionais, a referida afirmação se apresenta como uma contradição. A despeito de um processo de construção, por vias da naturalização, de uma tipologia musical brasileira representativa de uma entidade dotada de "fisiopsicologia" apropriada, para a qual 
concorre o ritmo, como quer o pensamento marioandradino, o rock no Brasil produz um discurso que o associa a um sentido supostamente natural, proveniente da fisiologia e da biologia. Ao se associar ao corpo e contrariar a naturalidade nacional, o rock transcende a nacionalidade e, por conseguinte, o preceito nacional da MPB, que afinal se revela como uma construção discursiva.

Enquanto as convenções musicais que informam os paradigmas da MPB adquirem significados ao se associarem a uma concepção do "tipicamente brasileiro", o rock, ao incorporar as respectivas convenções musicais, como no recorrente emprego do paradigma que se caracteriza pela contrametricidade na quarta semicolcheia do compasso dois por quatro, problematiza os seus significados, sobretudo os relacionados com o problema da nacionalidade.

Em uma canção datada de 1971, o problema da nacionalidade aparece associado ao emprego de uma forma musical que, embora transcrita no compasso quatro por quatro, representa a mesma figura formada por "colcheia entre duas semicolcheias", concebida como signo de brasilidade:

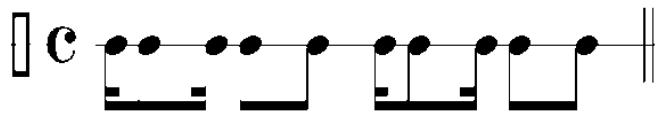

A respectiva forma musical representa o ritmo do cateretê, empregado em "Hoje ainda é dia de rock":
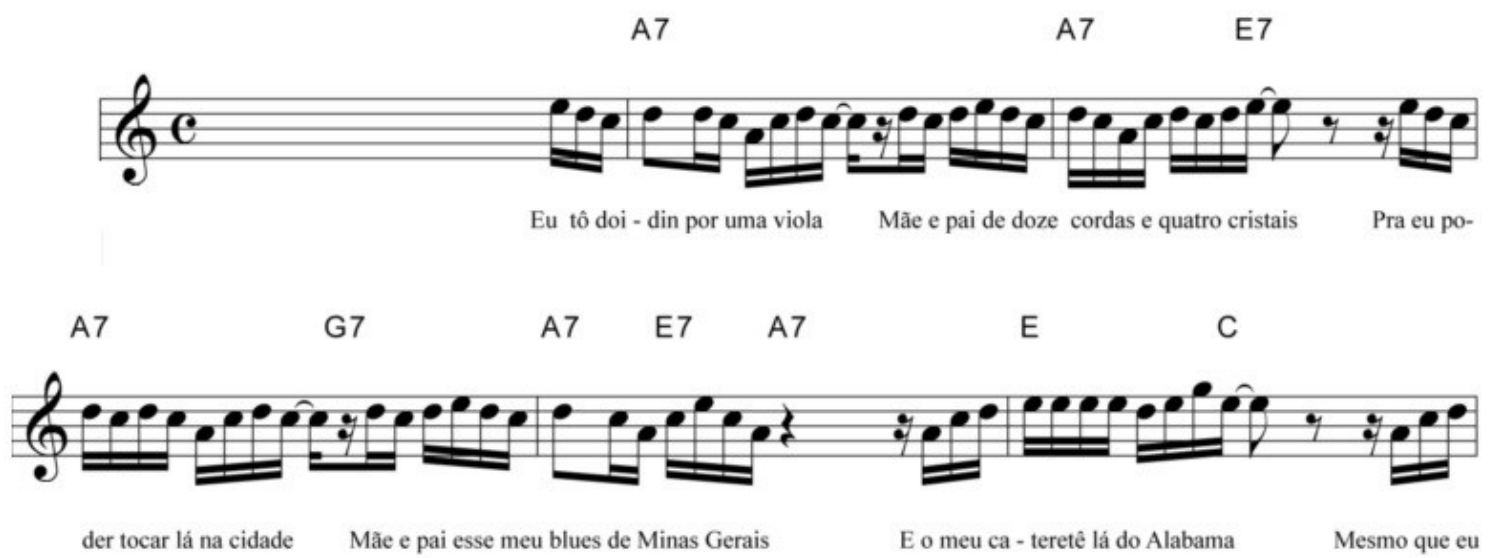

D

A7

G7

A7 $\quad$ E7 $\quad$ A7

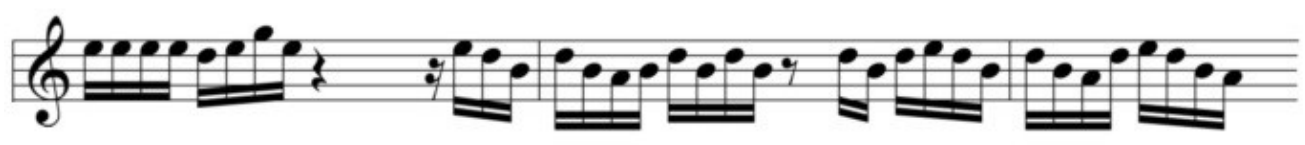

toque uma vezinha só

Eu desco - bri acho que foi a tempo Mãe e pai que hoje a - inda é di - a de rock

Eu tô doidin por uma viola

Mãe e pai de doze cordas e quatro cristais

Pra eu poder tocar lá na cidade

Mãe e pai esse meu blues de Minas Gerais 
E o meu cateretê lá do Alabama

Mesmo que eu toque uma vezinha só

Eu descobri acho que foi a tempo

Mãe e pai que hoje ainda é dia de rock

Ao se apropriar de um ritmo considerado nacional a partir de premissas musicais associadas ao ritmo do rock, a canção opera uma deformação que a letra, por meio de uma variedade da linguagem empregada no interior do estado de Minas Gerais, explicita nos versos em que equipara o "meu blues de Minas Gerais" ao "meu cateretê lá do Alabama", subvertendo as origens dos ritmos dos seus respectivos estados. Na medida em que os contrastes constituem temas recorrentes para o sujeito da canção interpelado por polaridades contrastantes, o sujeito, cuja descoberta de que "hoje ainda é dia de rock" ocorre "olhando o milho verde" e "ouvindo a mula preta", aparece (des)situado entre as polaridades contrastantes.

Outra canção, denominada "Corta Jaca", cuja letra questiona a unidade do ritmo “"tão pensando que isso é rock and roll?" - submete ritmicamente o acento do compasso quatro por quatro do ritmo do rock and roll ao acento do compasso dois por quatro do ritmo do xote:

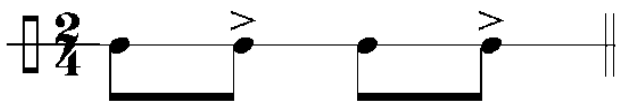

A letra problematiza os contrastes que fundamentam os discursos folcloristas, como o rural e o urbano, o passado e o presente, conjeturando que "Cortar jaca na cidade não é mole não":
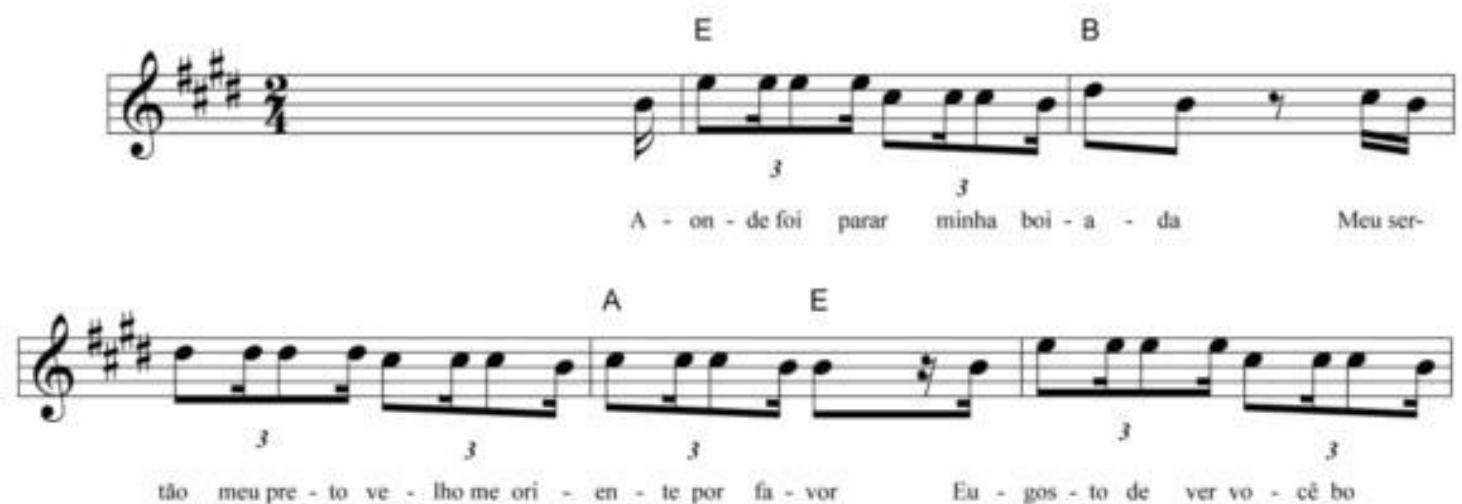

tâo meu pre - to ve - the me ori - en - te por fa - vor Eu - gos - to de ver vo - cể bo 


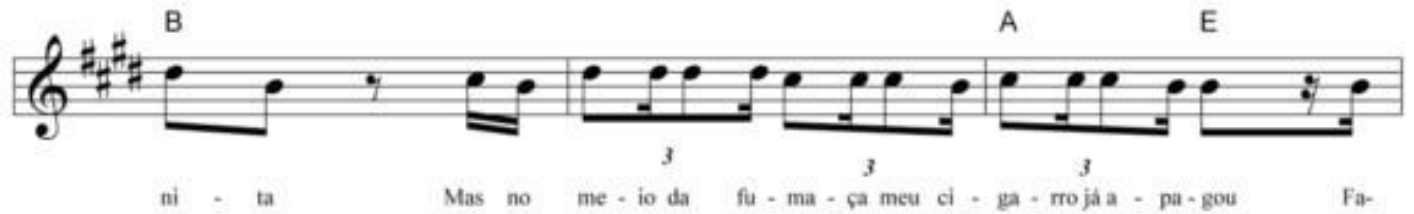

B

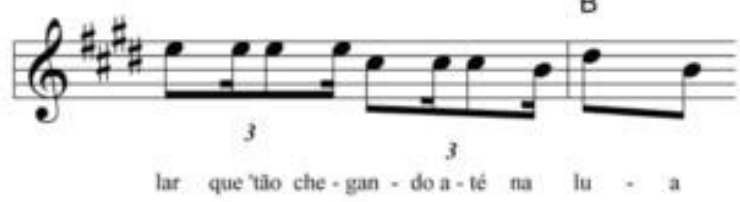

Aonde foi parar minha boiada

Meu sertão meu preto velho me oriente por favor

Eu gosto de ver você bonita

Mas no meio da fumaça o meu cigarro já apagou

Falar que tão chegando até na lua...

Ao submeter o acento do compasso quatro por quatro do ritmo do rock and roll ao acento do compasso dois por quatro do ritmo do xote, a canção produz um shuffle com o acento do ritmo do xote. O shuffle caracteriza o ritmo tercinado do blues e do rhythm and blues, dos quais se origina o rock and roll, que abandona o tercinado pela dinamização do ritmo. Ao deformar ambos os ritmos, portanto, "Corta Jaca" apresenta um shuffle caracterizado por uma sonoridade que se poderia denominar, apenas contraditoriamente, "tipicamente brasileira" ou "caracteristicamente nacional", uma vez que neutraliza a identidade, sobretudo quanto a aspectos de nacionalidade:

B

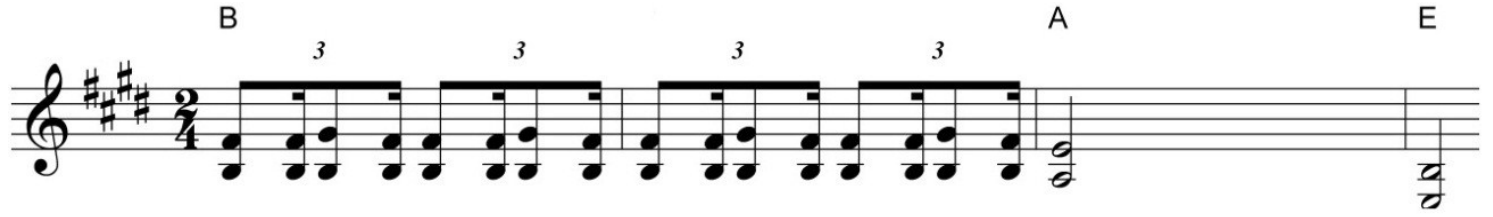

O shuffle acima difere, portanto, do shuffle tradicional do rock and roll, caracterizado pela cometricidade do modelo tercinado que constitui o ritmo do blues e do rhythm and blues, exatamente como aparece na seguinte canção dos Mutantes: 

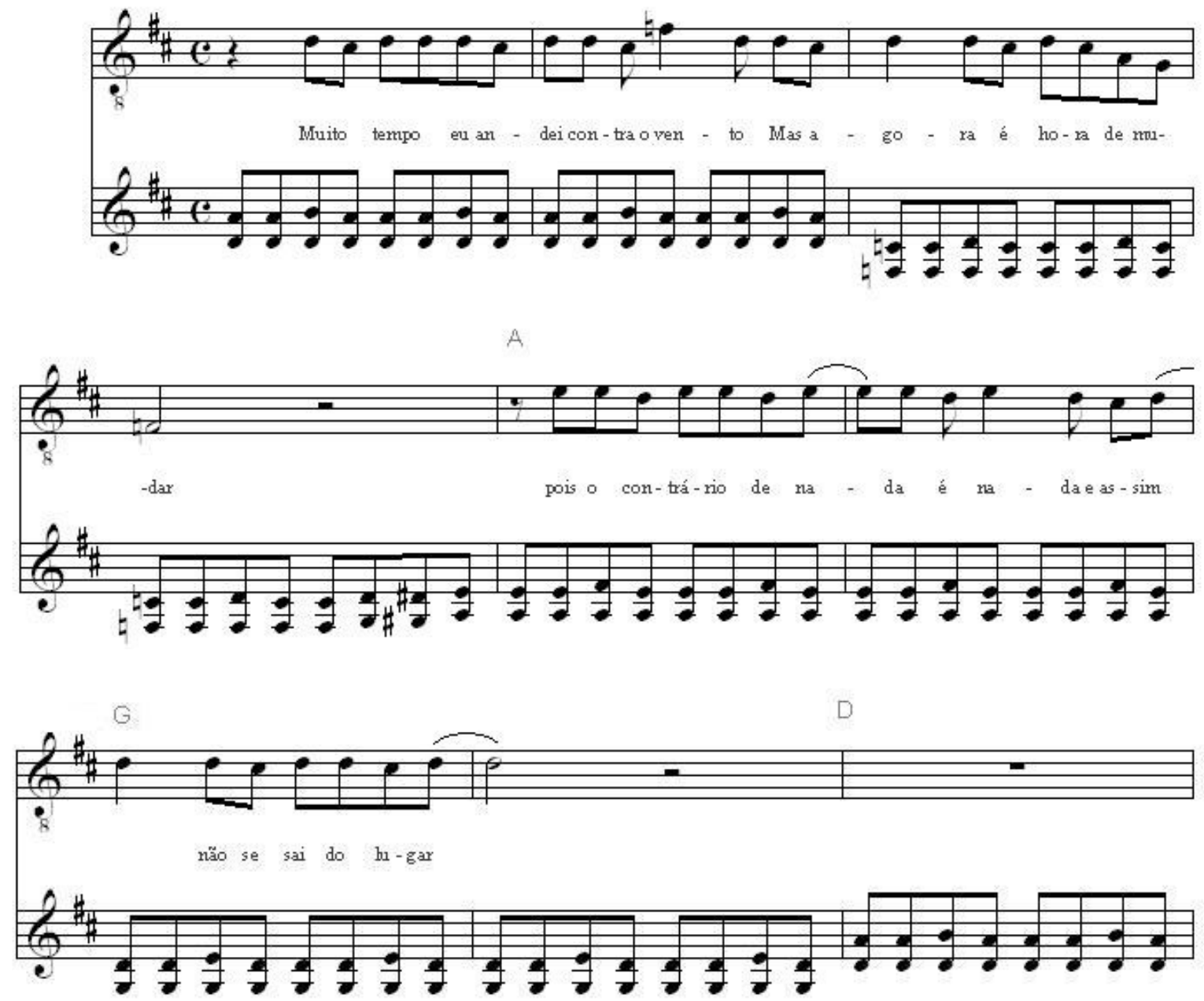

Muito tempo eu andei contra o vento

Mas agora é hora de mudar

Pois o contrário de nada é nada

E assim não se sai do lugar

Aqui interessa reter dos versos, que neutralizam as polaridades opostas de uma oposição, o gesto que, talvez aludindo aos versos de Caetano Veloso - "Caminhando contra o vento..." - e consoante ao ritmo que o sustenta, pretende, ao refutar a "linha evolutiva" da MPB representada pelo Tropicalismo, fundar um lugar enunciativo ao rock and roll no Brasil, como confirma o refrão:

E se você quiser saber onde eu fico é só me escutar

Rock'n'roll yeah! Rock'n'roll yeah!

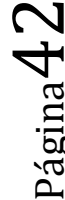

Rock'n'roll yeah! Rock'n'roll yeah! 
Com efeito, o referido gesto prolifera entre as bandas de rock no Brasil dos anos 1970, a exemplo dos versos de uma canção registrada no primeiro disco da Patrulha do Espaço depois de Arnaldo Baptista, datado de 1978:

\author{
Eu vou pra qualquer lugar \\ Aonde eu possa tocar \\ E não quero pensar muito pra onde eu vou \\ Mas onde estiver eu sou mais rock and roll
}

Os versos dos Mutantes, no entanto, compreendem a possibilidade de uma interpretação particular, qual seja, a de uma mudança do Tropicalismo para o rock and roll, fundamentada no verbo 'mudar': "Muito tempo eu andei contra o vento, mas agora é hora de mudar...", tal como reaparece nos versos de uma canção do disco seguinte, gravado ao vivo em 1976:

\footnotetext{
Viajando para rock and roll city

Sinto muito mas não vou escutar

Estou voando para rock and roll city

Não espere que eu não vou mais voltar

Estou mudando para rock and roll city

E não há nada que me faça parar
}

Afinal, se no final dos anos 1960 os Mutantes integram o Tropicalismo, a partir dos anos 1970, abdicam do movimento de continuidade da tradição da MPB e afirmam uma identidade propriamente roqueira, como exprime o sujeito da canção, de modo que o abandono dos ritmos brasileiros, conforme Carlos Calado (1995, p. 300) reduz a banda a "uma sombra de si mesma".

No processo de polarização, enfim, que, concomitantemente ao processo de nacionalização do samba nos anos 1930, considerado ritmo nacional mantenedor da identidade nacional, dividiu a sociedade brasileira, o Tropicalismo, conforme a natureza da alegoria, ${ }^{5}$ sintetiza dialeticamente as polaridades, culturalmente representadas nos anos 1960, por um lado, pela MPB e, por outro, pelo rock.

Se, como sugere Middleton (1990, p. 18), o rock and roll se caracteriza por uma contraditoriedade interna e por se inserir entre as polaridades no interior da contradição de modo a organizar o problema de maneira particular, a MPB, por outro lado, pelo sentido de nacionalidade que adquire, constitui uma polaridade da contradição. A MPB articula a oposição de uma cultura nacional a uma cultura estrangeira ao delimitar uma

\footnotetext{
${ }^{5}$ Ao diferenciar o símbolo e a alegoria, Walter Benjamin (1984, p. 187) afirma que "a alegoria não está livre de uma dialética correspondente", de modo que o estudo da forma do drama barroco alemão revela "a violência desse movimento dialético": "O amplo horizonte que Görres e Creuzer atribuem à intenção alegórica, enquanto história natural, pré-história da significação ou da intenção, é de natureza dialética. A relação entre o símbolo e a alegoria pode ser compreendida, de forma persuasiva e esquemática, à luz da decisiva categoria do tempo, que esses pensadores da época romântica tiveram o mérito de introduzir na esfera da semiótica".
} 
autenticidade que supostamente se realiza nas manifestações populares e regionais que reafirmariam a identidade nacional, contribuindo para o estabelecimento de um paradigma firmado na nacionalidade. E o Tropicalismo, ao sintetizar dialeticamente as oposições, confirma o referido paradigma preservado pela MPB. Afinal, como afirma Napolitano (2001, p. 343), a pluralidade e as contradições, "como em todo processo de institucionalização de uma determinada expressão cultural", "tendem a se perder".

A partir do processo de incorporação de caracteres preestabelecidos nos discursos acerca do que se compreende como nacional, o rock, ao problematizar as polaridades contrastantes representadas pelo rock e pela MPB, potencializa as polaridades, mas as equiparando e preservando o conflito. O rock no Brasil dos anos 1970 produz, assim, por meio de um procedimento que se nega a operar logicamente ou dialeticamente, um discurso sobre a identidade sob o signo de uma contradição permanentemente contradita.

Para tanto, o rock apresenta recorrentemente o seu sujeito (des)situado entre as polaridades contrastantes, o eu e o outro, o urbano e o rural, o presente e o passado, o rock e a MPB, de modo que o sujeito afirma e nega a identidade a partir de um lugar no qual a polaridade aparece e desaparece. Ao problematizar a unidade convencionada a partir de uma identidade nacional e uma cultura brasileira, fundamentada na contraposição com o outro, o rock representa o aparecimento e o desaparecimento de cada categoria e, por conseguinte, da possibilidade de unidade de cada categoria.

\section{REFERÊNCIAS}

ALBIN, Ricardo Cravo. O livro de ouro da MPB: a história de nossa música popular de sua origem até hoje. 2. ed. Rio de Janeiro: Ediouro, 2003.

ANDRADE, Mário de. Música, doce música. 2. ed. São Paulo: Martins; Brasília: INL, 1976.

BARBOSA, Airton Lima (Org.). Que caminho seguir na música popular brasileira? In: REVISTA CIVILIZAÇÃO BRASILEIRA. Rio de Janeiro, n. 7, p. 375-385, maio 1966.

BASUALDO, Carlos. Vanguarda, cultura popular e indústria cultural no Brasil. In: BASUALDO, Carlos (Org.). Tropicália: uma revolução na cultura brasileira (1967-1972). São Paulo: Cosac Naify, 2007.

BENJAMIN, Walter. Origem do drama barroco alemão. Tradução de Sergio Paulo Rouanet. São Paulo: Brasiliense, 1984.

BENJAMIN, Walter. Magia e técnica, arte e política. $7^{\mathrm{a}}$ ed. Tradução de Sergio Paulo Rouanet. São Paulo: Brasiliense, 1994.

CALADO, Carlos. A divina comédia dos Mutantes. Rio de Janeiro: 34, 1995.

CAMPOS, Augusto de. Balanço da bossa e outras bossas. 5. ed. São Paulo: Perspectiva, 2008. (Debates)

COLI, Jorge. Música Fical: Mário de Andrade e sua coluna jornalística Mundo Musical. Campinas: UNICAMP, 1998.

DUNN, Christopher. Tropicália: modernidade, alegoria e contracultura. In: BASUALDO, Carlos (Org.). Tropicália: uma revolução na cultura brasileira (1967-1972). São Paulo: Cosac Naify, 2007.

MELLO, Zuza Homem de. A era dos festivais: uma parábola. São Paulo: 34, 2003.

MIDDLETON, Richard. Studying popular music. Philadelphia: Open University Press, 1990.

NAPOLITANO, Marcos. Seguindo a canção: engajamento político e indústria cultural na MPB (19591969). São Paulo: Annablume/Fapesp, 2001. 
NAPOLITANO, Marcos; WASSERMAN, Maria Clara. Desde que samba é samba: a questão das origens no debate historiográfico sobre música popular brasileira. In: REVISTA BRASILEIRA DE HISTÓRIA. São Paulo, v. 20, n. 39, p. 157-189, 2000.

SANDRONI, Carlos. Adeus à MPB. In: CAVALCANTE, Berenice et al.(Org.). Decantando a República. Rio de Janeiro: Nova Fronteira, 2004.

SANDRONI, Carlos. Feitiço Decente: transformações do samba no Rio de Janeiro (1917-1933). Rio de Janeiro: J. Zahar; UFRJ, 2001.

SCHWARZ, Roberto. Cultura e política: 1964-1969. In: SCHWARZ, Roberto. O pai de família e outros estudos. Rio de Janeiro: Paz e Terra, 1978.

DISCOGRAFIA

ARNALDO \& A PATRULHA DO ESPAÇO. Corta jaca. In: ARNALDO \& A PATRULHA DO ESPAÇO. Elo perdido. São Paulo: Vinil Urbano, 1988. 1 disco sonoro. Lado A, faixa 3 (3min 55s). MADE IN BRAZIL. Aquarela do Brasil. In: MADE IN BRAZIL. Made in Brazil. São Paulo: RCA Victor, p1974. 1 disco sonoro. Lado A, faixa 4 (2min 49s).

MADE IN BRAZIL. Uma banda made in Brazil. In: MADE IN BRAZIL. Paulicéia desvairada. São Paulo: BMG, 1978. 1 disco sonoro. Lado B, faixa 1.

MUTANTES. O contrário de nada é nada. In: MUTANTES. Tudo foi feito pelo sol. Rio de Janeiro: Som Livre, 1974. 1 disco sonoro. Lado B, faixa 3 (2 min 58s).

MUTANTES. Rock'n'roll city. In: MUTANTES. Ao vivo. Rio de Janeiro: Som Livre, 1977. 1 disco sonoro. Lado B, faixa 3 (6 min 30s).

PATRULHA DO ESPAÇO. Role da estrada. In: PATRULHA DO ESPAÇO. Dossiê volume 1: 1978/1981. São Paulo: Independente, 1997. CD. Faixa 4 (2min 21s).

PERFUME AZUL DO SOL. O abraço do baião. In: PERFUME AZUL DO SOL. Nascimento. São Paulo: Chantecler, 1974. 1 disco sonoro. Lado A, faixa 5 (2min 53s).

SÁ, RODRIX E GUARABIRA. Hoje ainda é dia de rock. In: SÁ, RODRIX E GUARABIRA. Passado, presente, futuro. São Paulo: Odeon, 1971. 1 disco sonoro. Lado A, faixa 6 (2min 19s).

SEIXAS, Raul. As aventuras de Raul Seixas na cidade de Thor. In: SEIXAS, Raul. Gita. São Paulo: Philips, 1974. 1 disco sonoro. Lado A, faixa 3 (3min 40s).

SEIXAS, Raul. Let me sing, let me sing. In: SEIXAS, Raul. Let me sing my rock'n'roll. São Paulo: Independente, 1985. 1 disco sonoro. Lado A, faixa 1 (3min 15s).

Recebido em 27/05/2014. Aprovado em 15/06/2014

Title: The Tropicalist allegory on the avenue of historicism: Tropicalism and rock in Brazil Author: Tiago Hermano Breunig; Jair Tadeu da Fonseca

Abstract: Since its consolidation in the Brazilian culture, the Tropicalism is designed by intellectuals as a form of representation of modern and national associated with allegory, which is related with the linear progress of historicist historiography. Thus, the allegory seems as an update of Brazil's representations, so that Carlos Basualdo says that the Tropicalism intends to think the Brazilian national identity as an open process in continuous development and, therefore, the incorporation of the rock elements on it serves as a mean of updating the musical production in Brazil. If, on the one hand, the Tropicalism, according to the dialectical nature of the allegory, synthesizes the polarities represented by MPB and rock music, on the other hand, rock produces a counter-discourse of national identity through a procedure that refuses to operate logically or dialectically, which is the subject of this work.

Keywords: Rock. Tropicalism. Nacionalism. 